\title{
Heterogeneity in Billing for Medicare's Advance Care Planning Codes Among Physicians and Advanced Practitioners in 2016 and 2017
}

J Gen Intern Med 36(11):3601-3

DOI: $10.1007 / \mathrm{s} 11606-020-06553-\mathrm{Z}$

(C) Society of General Internal Medicine 2021

\section{INTRODUCTION}

Advance care planning (ACP), the process of discussing and recording patient preferences for goals of care in the event of the patient losing capacity has been widely acknowledged as key to ensuring care delivery concordant with patient preferences. ${ }^{1,2}$ Provider-perceived barriers to ACP have been documented, such as lack of time or reimbursement. ${ }^{3}$ Medicare began reimbursing providers for ACP in 2016. Previous studies found overall low rates of ACP billing, with wide variation by patient socio-demographics and physician specialty. ${ }^{4,5}$ Very little is known about the physician or practice characteristics associated with ACP billing, and no study has examined ACP billing among non-physician providers. We used a nationally representative sample to identify the characteristics of physicians and advanced practitioners (APs) associated with billing for ACP.

\section{METHODS}

We used a 20\% nationwide random sample of Medicare Part B claims for 2016 and 2017 merged with the Medicare Data on Provider Practice and Specialty, Medicare Shared Savings Program Provider Accountable Care Organization (ACO) Provider file, Medicare Electronic Health Records (EHR) Incentive Program (Meaningful Use) Public Use File, and IQVIA Physician Database. ${ }^{6}$ Our study population included physicians and APs (nurse practitioners and physician assistants) with 100 or more Part B claims in 2016 and in 2017. ACP billing was identified by current procedural terminology code 99497 or 99498 . We conducted logistic regression analyses predicting the probability of ACP billing using the following characteristics: age, gender, Meaningful Use participation, foreign medical school training, Medicare ACO participation, practice size, and rural location. We estimated the regressions separately for generalist physicians (internal

Received August 3, 2020

Accepted December 22, 2020

Published online January 22, 2021 medicine, family practice, geriatric medicine, general practice, hospitalists), specialist physicians, and APs.

\section{RESULTS}

Our study population included 551,441 physicians (179,356 generalists and 372,085 specialists) and 150,045 APs. Overall, $10.3 \%$ of generalists, $0.7 \%$ of specialists, and $4.2 \%$ of APs billed for ACP between 2016 and 2017, with small increases among each group (Table 1).

For physicians, and especially among generalists, ACP billing was significantly higher among those who participated in an ACO (adjusted odds ratio [aOR], 1.43; 95\% CI, 1.38 to $1.48 ; P<0.001)$ or in Meaningful Use (aOR, $1.49 ; 95 \% \mathrm{CI}$, 1.44 to $1.55 ; P<0.001$ ), and for those who were in smaller practices, relative to their counterparts (Table 2). In particular, generalists in practices with fewer than 10 physicians $(12.6 \%$; 95\% CI, 12.3 to $12.9 \%)$, with ACO participation (10.3\%; $95 \%$ $\mathrm{CI}, 10.1$ to $10.5 \%)$, and meaningful use participation (10.1\%; 95\% CI, 9.9 to $10.3 \%$ ) had the highest adjusted prevalence of ACP billing. Among specialists, those who were foreign trained $(0.9 \%$; $95 \% \mathrm{CI}, 0.8$ to $1.0 \%)$ and those participating in Meaningful Use $(0.8 \%$; $95 \%$ CI, 0.7 to $0.8 \%)$ had the highest adjusted prevalence of ACP billing. Analyses limited to the specialties with the highest prevalence of ACP billing (hematology/oncology, 1.9\%, and pulmonary Disease, 1.5\%) yielded similar results. For APs, the predicted prevalence of ACP billing was the highest among those in practices with fewer than 10 physicians $(5.4 \%$; $95 \%$ CI, 5.1 to $5.6 \%)$, with ACO participation $(4.4 \%$; $95 \%$ CI, 4.2 to $4.6 \%)$, and those who were female $(4.1 \%$; $95 \%$ CI, 4.0 to $4.2 \%)$.

\section{DISCUSSION}

We saw small absolute increases in ACP billing from 2016 to 2017. While generalist physicians accounted for over half of all providers who billed for ACP during this period, APs accounted for $23 \%$. The overall low prevalence of ACP billing masks substantial heterogeneity by provider and practice characteristics. ACO participation and Meaningful Use was associated with higher prevalence of ACP billing among physicians, especially generalists, suggesting that incentives and infrastructure for quality improvement and cost-saving may 
Table 1 Number and Percentage of Providers with ACP Billing, by Year and Provider Type

\begin{tabular}{|c|c|c|c|c|c|}
\hline \multirow[t]{2}{*}{ Provider type } & \multirow{2}{*}{$\begin{array}{l}\text { No. of total unique physicians } \\
\text { or APs }\end{array}$} & \multirow{2}{*}{$\begin{array}{l}2016 \\
\text { Billed ACP, no. } \\
(\%)\end{array}$} & \multirow{2}{*}{$\begin{array}{l}2017 \\
\begin{array}{l}\text { Billed ACP, no. } \\
(\%)\end{array}\end{array}$} & \multirow{2}{*}{$\begin{array}{l}\text { Percent increase from } 2016 \\
\text { to } 2017\end{array}$} & \multirow{2}{*}{$\begin{array}{l}\text { Total } \\
\text { Billed ACP, no. } \\
(\%)\end{array}$} \\
\hline & & & & & \\
\hline $\begin{array}{l}\text { Generalist } \\
\text { physicians }^{\mathrm{a}}\end{array}$ & 179,356 & $10,264(5.7)$ & $15,206(8.5)$ & $48.1 \%$ & $18,384(10.3)$ \\
\hline $\begin{array}{l}\text { Specialist } \\
\text { physicians }\end{array}$ & 372,085 & $1367(0.4)$ & $1977(0.5)$ & $44.6 \%$ & $2585(0.7)$ \\
\hline $\begin{array}{l}\text { Advanced } \\
\text { practitioners }\end{array}$ & 150,045 & $3014(2.0)$ & $5186(3.5)$ & $72.1 \%$ & $6350(4.2)$ \\
\hline
\end{tabular}

${ }^{a}$ Generalist physicians include physicians in internal medicine, family practice, geriatric medicine, general practice, or hospitalists

${ }^{b}$ Specialist physicians include all physicians other than generalist physicians

Table 2 Characteristics of Physicians and Advanced Practitioners and Advance Care Planning Billing

\begin{tabular}{|c|c|c|c|c|c|c|}
\hline \multirow[t]{2}{*}{ Variables } & \multicolumn{2}{|c|}{ Generalist physicians $^{\mathbf{a}}$} & \multicolumn{2}{|c|}{ Specialist physicians $^{b}$} & \multicolumn{2}{|c|}{ Advanced practitioners (PAs and NPs) } \\
\hline & No. $(\%)$ & $\begin{array}{l}\text { Adjusted prevalence } \\
\text { of ACP billing } \\
\% \text { (95\% CI) }\end{array}$ & No. $(\%)$ & $\begin{array}{l}\text { Adjusted prevalence } \\
\text { of ACP billing } \\
\% \text { ( } 95 \% \text { CI })\end{array}$ & No. $(\%)$ & $\begin{array}{l}\text { Adjusted prevalence } \\
\text { of ACP billing } \\
\text { \% }(95 \% \text { CI })\end{array}$ \\
\hline \multicolumn{7}{|l|}{ Sex } \\
\hline Female & $66,375(37.01)$ & $8.71(8.49$ to 8.93$)$ & $92,934(24.98)$ & $0.6(0.55$ to 0.65$)$ & $119,659(79.75)$ & 4.09 (3.97 to 4.20$)$ \\
\hline Male & $112,981(62.99)$ & $8.54(8.37$ to 8.7$)$ & $279,151(75.02)$ & $0.52(0.5$ to 0.55$)$ & $30,386(20.25)$ & 2.01 (1.86 to 2.17$)$ \\
\hline \multicolumn{7}{|l|}{ Age } \\
\hline$\leq 39$ & $39,729(22.15)$ & $10.22(9.88$ to 10.56$)$ & $71,570(19.23)$ & $0.68(0.61$ to 0.75$)$ & $66,071(44.03)$ & $3.22(3.09$ to 3.36$)$ \\
\hline$\overline{4} 0-49$ & $49,008(27.32)$ & $9.12(8.86$ to 9.38$)$ & $103,181(27.73)$ & $0.63(0.58$ to 0.67$)$ & $40,395(26.92)$ & $3.84(3.65$ to 4.03$)$ \\
\hline $50-59$ & $43,945(24.5)$ & $8.82(8.57$ to 9.08$)$ & $97,361(26.17)$ & $0.48(0.44$ to 0.52$)$ & $27,614(18.40)$ & $4.28(4.04$ to 4.51$)$ \\
\hline$\geq 60$ & $46,674(26.02)$ & $6.84(6.62$ to 7.07$)$ & $99,973(26.87)$ & $0.43(0.39$ to 0.47$)$ & 15,965 (10.64) & $3.92(3.62$ to 4.22$)$ \\
\hline \multicolumn{7}{|c|}{ Foreign trained ${ }^{\mathrm{d}}$} \\
\hline Yes & $60,722(33.86)$ & 9.34 (9.11 to 9.57$)$ & $77,883(20.93)$ & $0.89(0.83$ to 0.96$)$ & NA & NA \\
\hline No & $118,634(66.14)$ & $8.22(8.07$ to 8.38$)$ & $294,202(79.07)$ & $0.45(0.43$ to 0.47$)$ & NA & NA \\
\hline \multicolumn{7}{|c|}{ Participated in an $\mathrm{ACO}^{\mathrm{e}}$} \\
\hline Yes & $74,741(41.67)$ & $10.28(10.06$ to 10.5$)$ & $121,971(32.78)$ & $0.61(0.56$ to 0.65$)$ & $100,010(66.65)$ & $4.39(4.20$ to 4.58$)$ \\
\hline No & $104,615(58.33)$ & $7.45(7.30$ to 7.61$)$ & $250,114(67.22)$ & $0.51(0.48$ to 0.54$)$ & $50,035(33.35)$ & 3.33 (3.22 to 3.44$)$ \\
\hline \multicolumn{7}{|c|}{ Meaningful use $\mathrm{f}^{\mathrm{f}}$} \\
\hline Yes & $93,152(51.94)$ & $10.11(9.91$ to 10.31$)$ & $182,946(49.17)$ & $0.75(0.71$ to 0.79$)$ & $149,891(99.90)$ & $3.57(0.77$ to 6.37$)$ \\
\hline No & $86,204(48.06)$ & $7.03(6.86$ to 7.2$)$ & $189,139(50.83)$ & $0.35(0.32$ to 0.38$)$ & $154(0.10)$ & $3.66(3.56$ to 3.75$)$ \\
\hline \multicolumn{7}{|l|}{ Practice size ${ }^{\mathrm{g}}$} \\
\hline $1-9$ & $54,520(30.4)$ & $12.59(12.28$ to 12.89$)$ & $109,300(29.38)$ & $0.63(0.58$ to 0.68$)$ & $31,604(21.06)$ & $5.35(5.09$ to 5.60$)$ \\
\hline $10-49$ & $28,082(15.66)$ & $9.37(9.03$ to 9.72$)$ & $82,200(22.09)$ & $0.55(0.5$ to 0.6$)$ & $36,876(24.58)$ & $3.98(3.78$ to 4.19$)$ \\
\hline $50-99$ & $16,979(9.47)$ & 7.25 (6.87 to 7.64$)$ & $33,931(9.12)$ & $0.65(0.56$ to 0.73$)$ & $17,187(11.45)$ & $4.16(3.86$ to 4.46$)$ \\
\hline$\geq 100$ & 79,775 (44.48) & $6.32(6.16$ to 6.49$)$ & $146,654(39.41)$ & $0.46(0.43$ to 0.49$)$ & 64,378 (42.91) & $2.61(2.49$ to 2.73$)$ \\
\hline \multicolumn{7}{|l|}{ Rural $^{\mathrm{h}}$} \\
\hline Yes & $21,837(12.18)$ & $7.27(6.93$ to 7.61$)$ & $27,853(7.49)$ & $0.6(0.51$ to 0.7$)$ & $20,898(13.93)$ & $2.73(2.52$ to 2.95$)$ \\
\hline No & $157,519(87.82)$ & $8.8(8.66$ to 8.94$)$ & $344,232(92.51)$ & $0.54(0.51$ to 0.56$)$ & $129,147(86.07)$ & $3.83(3.72$ to 3.93$)$ \\
\hline Observations & 179,356 & 179,356 & 372,085 & 372,085 & 150,045 & 150,045 \\
\hline
\end{tabular}

ACP, advance care planning; AP, advanced practitioners; CI, confidence interval; PA, physician assistant; NP, nurse practitioner; NA, not applicable; $A C O$, accountable care organization

All unique providers from 2016 through 2017 were included in the table. Listed characteristics were from the most recent available year (2017 or 2016). Among generalist physicians, specialists, and advanced practitioners, the probability of billing ACP varied significantly by gender, age (each category compared to the reference group: $\leq 39$ ), foreign-trained/non-foreign-trained status, participation status in an ACO, participation status in the Meaningful Use program, practice size (each category compared to the reference group: 1-9 providers), and rural/urban status at 1\% level with the following exceptions: (1) among generalist physicians, there was no significant difference by gender $(P=0.21)$; (2) among specialists, there was no significant difference between those aged 40 to 49 years old and those aged below 40 years old $(P=0.20)$, between those in practices with 50 to 99 physicians and those in practices with 1 to 9 physicians $(P=0.78)$, or between those in the rural area and those in the non-rural area $(P=0.15) ;(3)$ among advanced practitioners, there was no significant difference by participation in the Meaningful Use program $(P=0.95)$

${ }^{a}$ Generalist physicians include physicians in internal medicine, family practice, geriatric medicine, general practice, or hospitalists

${ }^{b}$ Specialist physicians include all physicians other than generalist physicians

${ }^{c}$ The adjusted prevalence is the predicted probability calculated using the postestimation margins command following multivariable logistic regression analysis where any advance care planning billing is a function of all the variables listed in the table

${ }^{d}$ The IQVIA Physician Database was used to identify medical schools attended by physicians. Foreign trained indicates physicians who attended medical school (not including postgraduate training) outside the USA

${ }^{e}$ The Medicare Shared Savings Program Accountable Care Organization Provider file was used to identify clinicians participating in Accountable Care Organizations

${ }^{f}$ The Medicare EHR Incentive Program Public Use File was used to identify meaningful use stage 1 certification

${ }^{g}$ Practice size was defined as the number of unique National Provider Identifiers in the practice

${ }^{h}$ Rural-Urban Continuum Codes 2013 from Area Health Resources Files (AHRF) was used to define rural. Providers were categorized as non-rural if the code was in 01,02,03 and as rural otherwise 
be conductive to ACP billing. Additionally, providers in small practices across all types had higher prevalence of ACP billing, possibly reflecting closer and longer-term patient-provider relationships in those practices.

Our findings suggest that particular aspects of provider incentives or practice environment may be more conducive to ACP billing. However, the relationships we present are associational, and evidence is still lacking regarding the extent to which providers address ACP without billing for it, or whether ACP billing is associated with improved care quality or lower spending. Further research is needed to address these questions and establish causal mechanisms to inform appropriate incentives and environment for ACP adoption and delivery of preference-concordant care.

Jing $L i, P h D^{1}$

Yuting Bian, $M S^{1}$

Hye-Young Jung, $\mathrm{Ph} \mathrm{D}^{1}$

${ }^{1}$ Department of Population Health Sciences, Weill Cornell Medical College,

New York, NY, USA

Corresponding Author: Hye-Young Jung, PhD; Department of Population Health Sciences, Weill Cornell Medical College, New York, NY, USA (e-mail: arj2005@med.cornell.edu).
Funding Dr. Li is the recipient of a JumpStart Career Development Award from Weill Cornell Medical College and a Mentored Research Scientist Development Award from the National Institute on Aging (K01AG066946). Dr. Jung is the recipient of a Mentored Research Scientist Development Award from the National Institute on Aging (K01AG057824).

\section{REFERENCES}

1. Bischoff KE, Sudore R, Miao Y, Boscardin WJ, Smith AK. Advance care planning and the quality of end-of-life care in older adults. J Am Geriatr Soc 2013;61(2):209-214.

2. Harrison KL, Adrion ER, Ritchie CS, Sudore RL, Smith AK. Low Completion and Disparities in Advance Care Planning Activities Among Older Medicare Beneficiaries. JAMA Intern Med 2016;176(12):1872-1875.

3. Ramsaroop SD, Reid M, Adelman RD. Completing an advance directive in the primary care setting: what do we need for success? J Am Geriatr Soc 2007;55(2):277-283.

4. Belanger E, Loomer L, Teno JM, Mitchell SL, Adhikari D, Gozalo PL. Early Utilization Patterns of the New Medicare Procedure Codes for Advance Care Planning. JAMA Intern Med. 2019;179(6):829-830.

5. Tsugawa $\mathbf{Y}$, Kato $\mathbf{H}$, Jha $\mathbf{A K}$, et al. Characteristics of Physicians Who Adopted Medicare's New Advance Care Planning Codes in the First Year. J Gen Intern Med. 2020;35(6): 1914-1916.

6. Cohen GR, Jones DJ, Heeringa J, et al. Leveraging Diverse Data Sources to Identify and Describe U.S. Health Care Delivery Systems. EGEMS (Wash DC). 2017;5(3):9.

Publisher's Note: Springer Nature remains neutral with regard to jurisdictional claims in published maps and institutional affiliations. 